\title{
Effect of Neurofeedback Facilitation on Poststroke Gait and Balance Recovery
}

\author{
A Randomized Controlled Trial
}

\begin{abstract}
Masahito Mihara, MD, PhD, Hiroaki Fujimoto, MD, PhD, Noriaki Hattori, MD, PhD, Hironori Otomune, MD, Yuta Kajiyama, MD, Kuni Konaka, MD, PhD, Yoshiyuki Watanabe, MD, PhD, Yuichi Hiramatsu, MSc, PhD, Yoshihide Sunada, MD, PhD, Ichiro Miyai, MD, PhD, and Hideki Mochizuki, MD, PhD
\end{abstract}

Neurology ${ }^{\circledR}$ 2021;96:e2587-e2598. doi:10.1212/WNL.0000000000011989

\section{Abstract}

\section{Objective}

To test the hypothesis that supplementary motor area (SMA) facilitation with functional nearinfrared spectroscopy-mediated neurofeedback (fNIRS-NFB) augments poststroke gait and balance recovery, we conducted a 2-center, double-blind, randomized controlled trial involving 54 Japanese patients using the 3-meter Timed Up and Go (TUG) test.

\section{Methods}

Patients with subcortical stroke-induced mild to moderate gait disturbance more than 12 weeks from onset underwent 6 sessions of SMA neurofeedback facilitation during gait- and balancerelated motor imagery using fNIRS-NFB. Participants were randomly allocated to intervention (28 patients) or placebo (sham: 26 patients). In the intervention group, the fNIRS signal contained participants' cortical activation information. The primary outcome was TUG improvement 4 weeks postintervention.

\section{Results}

The intervention group showed greater improvement in the TUG test $(12.84 \pm 15.07$ seconds, 95\% confidence interval 7.00-18.68) than the sham group ( $5.51 \pm 7.64$ seconds, $95 \%$ confidence interval 2.43-8.60; group difference 7.33 seconds, 95\% CI 0.83-13.83; $p=0.028$ ), even after adjusting for covariates (group $\times$ time interaction; $F_{1.23,61.69}=4.50, p=0.030$, partial $\eta^{2}=0.083$ ). Only the intervention group showed significantly increased imagery-related SMA activation and enhancement of resting-state connectivity between SMA and ventrolateral premotor area. Adverse effects associated with fNIRS-mediated neurofeedback intervention were absent.

\section{Conclusion}

SMA facilitation during motor imagery using fNIRS neurofeedback may augment poststroke gait and balance recovery by modulating the SMA and its related network.

\section{Classification of Evidence}

This study provides Class III evidence that for patients with gait disturbance from subcortical stroke, SMA neurofeedback facilitation improves TUG time (UMIN000010723 at UMINCTR; umin.ac.jp/english/).

\author{
Correspondence \\ Dr. Mihara \\ mihara@ \\ med.kawasaki-m.ac.jp
}

\section{RELATED ARTICLE \\ Editorial}

Facilitating Mental Imagery to Improve Mobility After Stroke: All in the Head

Page 975

\section{MORE ONLINE}

- Video

$\rightarrow$ Class of Evidence

Criteria for rating

therapeutic and diagnostic studies

NPub.org/coe 


\section{Glossary}

ACC $=$ anterior cingulate cortex $\mathbf{B B S}=$ Berg Balance Scale $; \mathbf{F}-\mathbf{M}=$ Fugl-Meyer motor assessment scale $;$ FDR $=$ false discovery rate; FIM = Functional Independence Measure; fNIRS-NFB = functional near infrared spectroscopy-mediated neurofeedback; GLM = general linear model; IFG = inferior frontal gyrus; MCID = minimal clinically important difference; MMSE = MiniMental State Examination; PMv = ventral premotor; post1 = immediately after intervention; post 2 = 2 weeks after intervention; RM-ANCOVA = repeated-measures analysis of covariance; rsfMRI = resting-state functional MRI; SMA = supplementary motor area; TUG $=$ Timed Up and Go test.

Poststroke gait and balance dysfunction affects overall quality of life, ${ }^{1,2}$ and even after rehabilitation, $20 \%-30 \%$ of patients cannot walk independently. ${ }^{1-4}$ Studies have shown that most recovery occurs within the first 12 weeks after onset, with limited recovery thereafter. ${ }^{5,6}$

Based on findings that functional reorganization of the neural network is essential for poststroke functional recovery, neuromodulation facilitating plastic reorganization is a viable target for research. ${ }^{7}$ Neurofeedback is a neuromodulation technique where a patient learns how to regulate neural activity using brain activity feedback. ${ }^{8,9}$ Because of its safety and portability, functional near-infrared spectroscopy-mediated neurofeedback (fNIRS-NFB) may be a promising technique for patients poststroke. Previous small pilot studies have revealed the feasibility and efficacy of fNIRS-NFB on upper limb recovery. ${ }^{9-12}$

In neuromodulation, the target cortical area is selected based on the desired effect; for example, the lateral motor areas for upper limb dysfunction ${ }^{10,13}$ and the parietal cortex for neglect. ${ }^{14}$ Therefore, making a priori determination of the appropriate targets for gait and balance recovery is important. Among various neural structures involved in gait and postural regulation, ${ }^{15}$ previous studies demonstrated the vital role of the cerebral cortex, especially the supplementary motor area (SMA) and its descending projections. ${ }^{3,11,16}$ Encouraged by a potentially beneficial effect on postural control in healthy young subjects, ${ }^{17}$ we conducted this 2-center, double-blind, randomized controlled trial to test the hypothesis that SMA facilitation with ANIRS-NFB would augment postural and gait recovery assessed by the 3-meter Timed Up and Go test (TUG). ${ }^{18,19}$

\section{Methods}

\section{Study Population}

This 2-center, double-blind, randomized controlled study is part of the exploratory project investigating the feasibility and efficacy of fNIRS-NFB in neurologic diseases. This project consists of 4 parallel randomized controlled studies targeting different symptoms and diseases using various intervention methods. Here we report the study targeting poststroke gait disturbance. In this study, we recruited patients with subcortical first-time stroke with hemiplegic gait disturbances from Osaka University Hospital (M.M.) and Morinomiya Hospital (H.F.) in Osaka, Japan. We included patients aged
20-85 years, having a first episode of subcortical ischemic or intraparenchymal hemorrhagic stroke with hemiplegia, and more than 12 weeks poststroke onset. Excluded patients were those with severe cognitive dysfunction or aphasia as screened by a Mini-Mental State Examination (MMSE) score of $<20$, severe carotid $(>90 \%)$ or intracerebral stenosis $(>75 \%)$, at tention deficit that may interfere with understanding the examiners' instructions, unilateral spatial neglect, large cortical lesion ( $>1 / 3$ of middle cerebral artery territory), unstable general condition, severe infection with scalp dermatitis, pregnant or lactating women, as well as patients considered not eligible for this study by the attending physician (see trial profile in figure 1).

\section{Study Design}

After enrollment, we assessed clinical background and baseline characteristics of the patients including age, sex, duration from onset, lesion side and location, cognitive status (MMSE), and side of hemiparesis. Enrolled patients were randomly allocated to real feedback and sham feedback groups by one of the authors (K.K.) who was not involved with intervention and evaluation, using a computer-generated sealed envelope method without any adjustment factors. Patients in both groups were provided with the customary rehabilitative intervention for at least 5 days a week. The daily duration of therapy was up to 180 minutes, including at least 60 minutes of physical therapy or occupational therapy. We did not regulate the precise methods or techniques, but therapies were optimized for each patient by the therapist in charge. After randomization, the patients were clinically assessed before neurofeedback intervention (preintervention), immediately after intervention (post1), and 2 weeks after intervention (post2). Patients in both groups were provided 6 sessions ( 3 times a week for 2 weeks) of neurofeedback training with gait and balance-related motor imagery (figure 2A). Patients were longitudinally assessed using the TUG, Functional Independence Measure (FIM), Fugl-Meyer motor assessment (F-M), Berg Balance Scale (BBS), and gait speed. Subjective and objective adverse effects were assessed at the time of clinical assessment and medical records were consulted retrospectively.

\section{Neurofeedback Intervention}

Details of the interventions were described previously. ${ }^{11}$ Briefly, each neurofeedback session consisted of a 10-minute instruction followed by neurofeedback training. At the start of each session, the participant watched a 10-minute video 


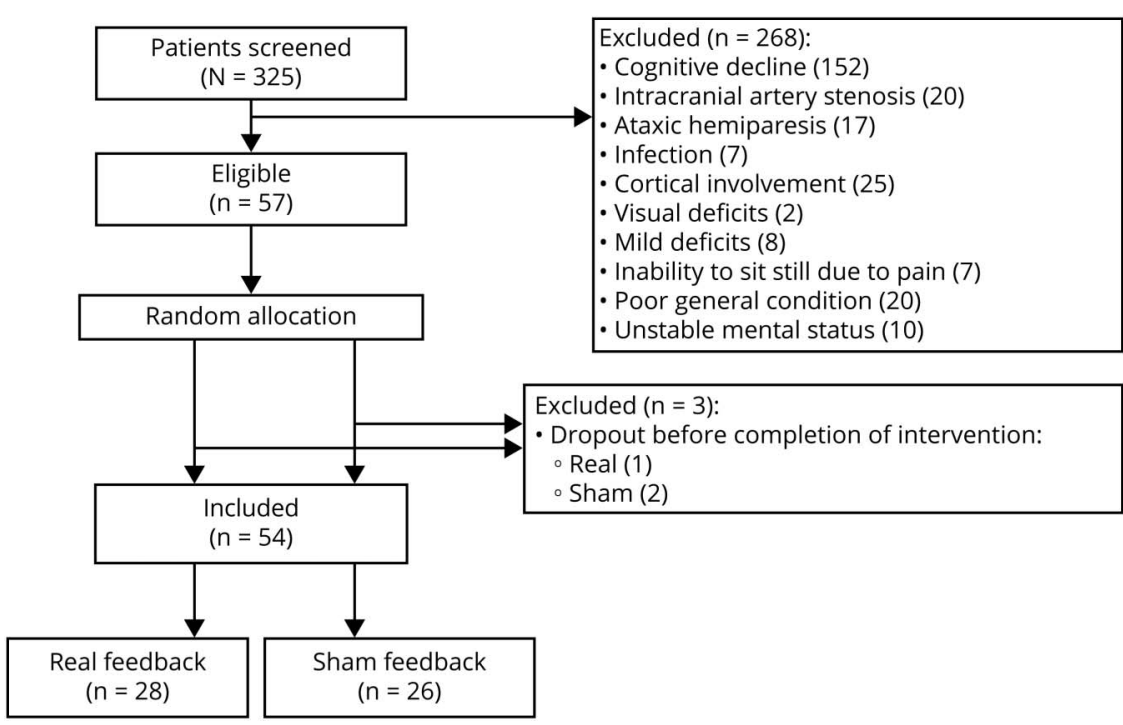

Out of the 325 patients with subcortical stroke screened, 57 patients who were eligible for this study were randomly allocated to the real feedback group and the sham feedback group. Three of those patients did not complete the intervention. Finally, data from 28 patients in the real feedback group and 26 patients in the sham feedback group were used for analysis. instruction of the kinesthetic motor imagery task, which consisted of a "rising up from the chair and stepping twice" task and a "walking along the corridor" task. Neurofeedback training targeting SMA activation was performed using the fNIRS-NFB system. ${ }^{10,20}$ Measured oxygenated hemoglobin signals were processed in real-time using a sliding-window general linear model (GLM) with least-square estimation, and calculated $t$ values for the task-related SMA activation change were used as feedback information. Patients were asked to perform kinesthetic motor imagery of both tasks and to try keeping the horizontal bar higher, which represents the SMA activation status. Patients in the real feedback group were provided signals representing their own SMA activation, whereas patients in the sham feedback group were provided signals representing prerecorded activation of other participants. Therefore, the sham feedback group could not learn how to regulate their cortical activity. The feedback task comprised 16 repetitions of a 5-second trial, with pseudorandomized interval ranging from 8 to $16 \mathrm{sec}$ onds. Patients in both groups performed the same training procedures, and the examiners, patients, and assessors were not aware of the group allocation (double-blinded).

\section{Study Outcomes}

The primary outcome was longitudinal changes in TUG time; the secondary outcomes were FIM, F-M, BBS, and gait speed. In addition to the clinical measures, resting-state functional MRI scans (rsfMRI) were obtained before and after intervention in patients who had no contraindication. We also evaluated intervention-related cortical activation changes using the motor imagery related cortical activation measured by fNIRS at the first and last neurofeedback session. Subjective adverse effects, including headache or faintness, were assessed by the interview at the end of each training session. In addition, we collected the number of falls, pain complaints including joint pain, headache, or lumbago, and other possible adverse events by reviewing medical records from enrollment to the planned final clinical assessment.

\section{fNIRS Data Acquisition and Analyses}

Details of fNIRS data acquisition and analyses have been described previously. ${ }^{10,20}$ In short, we used an fNIRS system (OMM-3000; Shimadzu Corp., Kyoto, Japan), and the oxygenated hemoglobin signal changes were considered as cortical activation changes. FNIRS measurement and intervention was conducted by trained researchers (H.O., Y.K., and Y.H.). Cortical activity was measured from 50 channels placed on the fronto-parietal scalp at $4 \mathrm{~Hz}$ (figure 2, B and C). Because we included patients with both right- and left-sided lesions, all imaging data from patients with a left-sided lesion were flipped horizontally before data analysis, so the affected hemisphere formed the right side of the image. For neurofeedback, real-time estimation of task-related signal changes were performed using adaptive GLM-based analysis with 20-second sliding time-window. ${ }^{10,17,20}$ The largest calculated $t$ values for the 4 channels covering the $\operatorname{SMA}(21,22,28$, and 29) were shown as the height and color of the vertical feedback bar. We recorded averaged feedback signal values for each patient.

For post hoc analysis of motor imagery-related cortical activation changes, fNIRS data were analyzed using an in-house developed program running on MATLAB. ${ }^{16}$ Using the first and last (6th) neurofeedback session data, we performed 2-tailed 1-sample $t$ tests to detect the imagery-related cortical activation. We also performed group comparison of the neurofeedback-related cortical activation changes using 2-tailed unpaired $t$ tests. Statistical significance was set at a false discovery rate (FDR)-corrected $q<0.05$. In the 


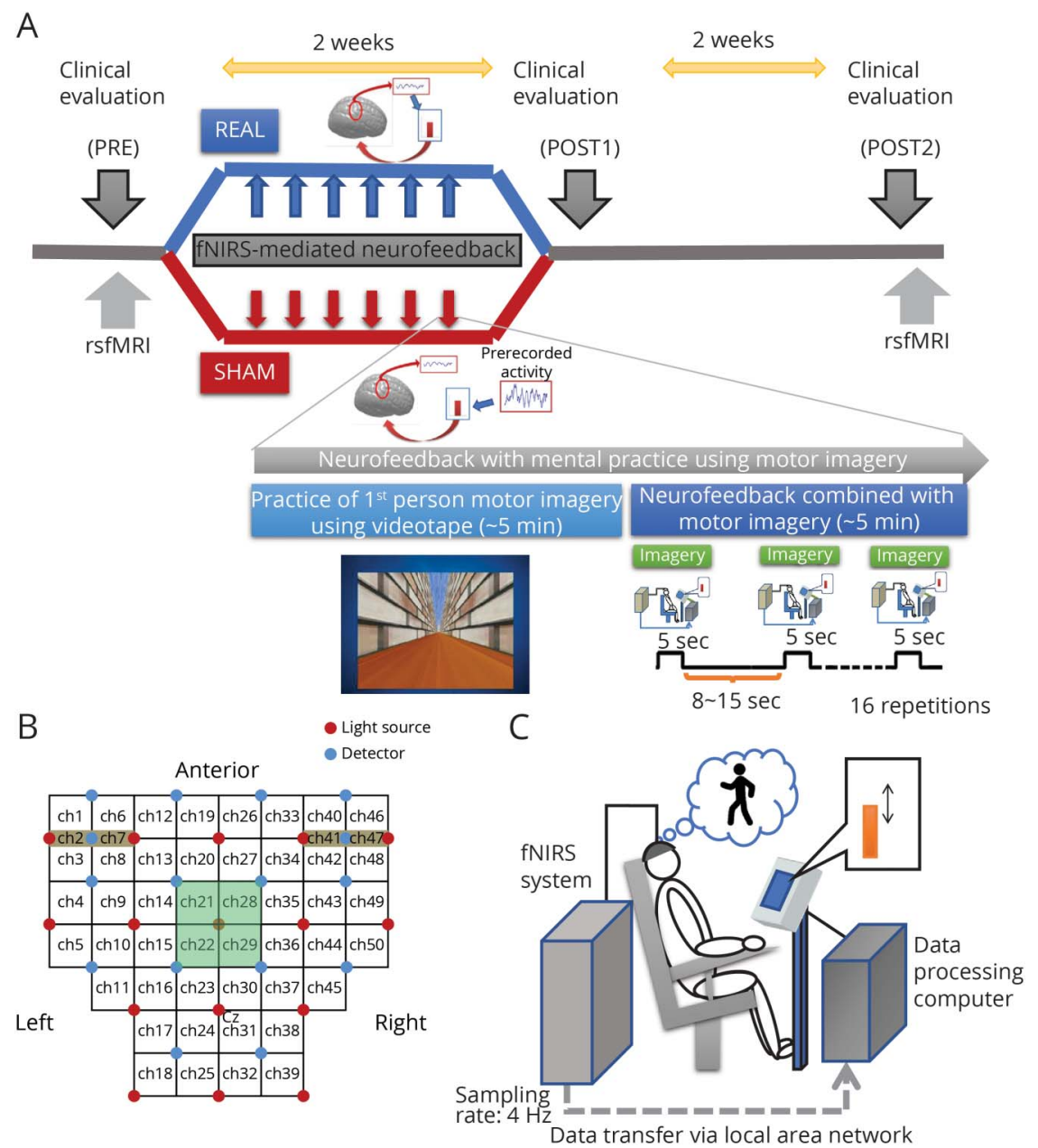

(A)Schematic illustration of the protocol for this study. Patients were randomly allocated to 2 groups, real feedback and sham feedback, and were subjected to 6 sessions of neurofeedback training combined with motor imagery. In the real group, the patients were provided with actual cortical activation during the motor imagery task, so they could learn how to regulate their cortical activation. In contrast, patients in the sham group were provided irrelevant information (other patients' recorded data) and therefore could not learn how to regulate their cortical activation. In the neurofeedback training sessions, patients were asked to practice the first-person motor imagery of the gait and balance task using videos. After practicing, the participants were requested to perform the motor imagery task without the video but with visual feedback of the vertical bar as a measure of appropriate supplementary motor area (SMA) activation. Neurofeedback practice was provided 3 times per week for 2 weeks, and clinical measures were evaluated before intervention (pre), just after intervention (post1), and 2 weeks postintervention (post2). (B) During neurofeedback sessions, participants' cortical activation was measured using fNIRS. fNIRS signals from the channels covering the fronto-parietal scalp and suspected to cover the SMA (channels 21, 22, 28, and 29) were used for real-time processing and calculation of the feedback signal. (C) Illustration depicts the experiment setup wherein a participant is sitting on a chair and performing a gait and balance-related motor imagery task. rsfMRI = resting-state functional
MRI.

channels revealed to be significant, we also performed channel-based Pearson correlation analysis between cortical activation changes and clinical improvement.

\section{MRI Data Acquisition and Analyses}

Structural MRI data were obtained for fNIRS channel registration and lesion configuration, and rsfMRI data were obtained (by N.H. and Y.W.) to determine whether neurofeedback could modulate resting-state functional networks. Because MRI scanners at the 2 facilities were different, we used only the data from the facility with the larger sample size (Morinomiya Hospital) for further rsfMRI analysis (Philips 1.5T Intera Achieva Nova [Philips Medical Systems, Best, the Netherlands]. Detailed measures are described in the supplementary information (doi.org/10.5061/dryad.sf7m0cg3n). For rsfMRI scans, we performed spin-echo echoplanar imaging and instructed participants to lay still with their eyes open and look at the fixation cross for 10 minutes. Lesion location was confirmed by anatomical scans, and individual lesion masks were manually generated. All rsfMRI analyses were performed with the CONN-fMRI Functional Connectivity toolbox v17 (nitrc. org/projects/conn). To reveal neurofeedback-related network changes, we investigated group difference of the individual SMA-seeded connectivity change map. We also investigated the cortical area with significant correlations between the SMA-seeded connectivity changes and clinical improvement. A threshold of uncorrected $p<0.001$ with FDR-corrected $q<0.05$ at the cluster level was considered to be statistically significant for imaging analysis.

\section{Statistical Analyses}

Statistical analysis for the clinical measures was conducted using IBM SPSS version 24 (IBM Corp.). Power analyses and a priori sample size estimation were conducted using $G^{*}$ Power with data from a previous study that investigated the fNIRS neurofeedback effect on poststroke upper limb paresis. ${ }^{10}$ Using these data and considering the $15 \%$ larger intersubject gait variability of pooled $\mathrm{SD}$, we calculated the effect size for a 2-group comparison (d) as 0.85 and the minimum sample size as 46 (23 for each group), with 2-tailed $\alpha$ of 0.05 and power $(1-\beta)$ of 0.80 . We could not estimate sample size needed to detect clinically significant improvement, because this is the first exploratory study investigating the effect of fNIRS-NFB on poststroke gait disturbance, and the minimal 
Table 1 Baseline Characteristics of Patients in Both Intervention Groups

\begin{tabular}{lll}
\hline & Real $(\mathbf{n}=\mathbf{2 8})$ & Sham $(\mathbf{n}=\mathbf{2 6})$ \\
\hline Age, $\mathbf{y}$ & $62.25 \pm 10.39$ & $60.08 \pm 12.33$ \\
\hline Duration from onset, $\mathbf{d}$ & $315.52 \pm 535.12$ & $462.96 \pm 764.67$ \\
\hline MMSE & $29.04 \pm 1.93$ & $28.96 \pm 1.97$ \\
\hline Male: female & $21: 7$ & $19: 7$ \\
\hline Ischemic: hemorrhagic & $12: 16$ & $15: 11$ \\
\hline Right: left hemiparesis & $17: 11$ & $14: 12$ \\
\hline 3-m TUG, s & $38.73 \pm 33.14$ & $27.93 \pm 17.28$ \\
\hline BBS & $36.71 \pm 9.48$ & $40.77 \pm 7.78$ \\
\hline Speed, m/s & $0.53 \pm 0.36$ & $0.61 \pm 0.41$ \\
\hline FIM total & $103.33 \pm 11.33$ & $102.88 \pm 12.17$ \\
\hline F-M upper & $33.29 \pm 17.84$ & $30.38 \pm 16.75$ \\
\hline F-M lower & $21.71 \pm 7.68$ & $21.38 \pm 5.97$ \\
\hline Daily therapy time, min & $123.96 \pm 21.81$ & $129.56 \pm 21.08$ \\
\hline Institution, OUH:MH & $5: 23$ & $5: 21$ \\
\hline
\end{tabular}

Abbreviations: 3-m TUG = 3-meter Timed Up and Go test; BBS $=$ Berg Balance Scale; F-M = Fugl-Meyer motor assessment scale; FIM = Functional Independence Measure; $\mathrm{MH}=$ Morinomiya Hospital; $\mathrm{MMSE}=$ Mini-Mental State Examination; OUH = Osaka University Hospital.

Data are presented as mean \pm SD or ratios.

clinically important difference (MCID) for TUG in patients with stroke is not established. To estimate the clinical effect of the fNIRS-NFB, we performed post hoc analysis using the largest minimal detectable change of TUG in stroke, as previously proposed ( 8.0 seconds). ${ }^{22}$ We performed $\chi^{2}$ test for investigating group differences in achieving more than 8 seconds improvement. We also calculated the absolute risk reduction for nonsignificant improvement in TUG by intervention with the fNIRS-NFB and calculated the number needed to treat to achieve clinically significant improvement in TUG.

Baseline characteristics, averaged feedback values, and averaged daily therapy duration were compared between groups using unpaired $t$ test (continuous measures) and $\chi^{2}$ test (categorical measures), as appropriate. Because the post onset duration of the participants was widely distributed, baseline characteristics were also compared between an early intervention group (enrolled within 150 days from onset) and late intervention group (enrolled after 150 days from onset).

We also performed an unpaired $t$ test between preintervention and post 2 for primary and secondary outcomes (TUG, BBS, gait speed, F-M, and FIM) to determine whether neurofeedback intervention over time has an augmenting effect on functional recovery. Next, a repeated-measures analysis of covariance (RM-ANCOVA) was conducted with the group as the between-subject factor and time (assessment periods) as the within-subject factor. In these adjusted models, the interaction term of group by time indicated whether neurofeedback was different between groups over time. The $p$ values were corrected for sphericity using the Greenhouse-Geisser correction, wherever necessary. Postonset duration and patient age, which could have a confounding effect on functional recovery, were included as covariates in the RM-ANCOVA. When a significant interaction term was observed, within-group post hoc $t$ tests with Bonferroni correction were conducted comparing post1 vs pre and post 2 vs pre.

\section{Standard Protocol Approvals, Registrations, and Patient Consents}

Written informed consent was obtained for all participants. The study was approved by the Research Ethics Boards at Osaka University Hospital (13,065-2) and registered at the University Hospital Medical Information Network Clinical Trials Registry (UMIN000010723 at UMIN-CTR umin.ac. jp/english/). Written consent to disclose was obtained from the patient who appeared in the supplementary video 1.

\section{Data Availability}

Three months after the publication of the study, individual anonymized participant data collected during the trial will be available to scientific researchers upon approval of the research proposal by the corresponding author.

\section{Results}

\section{Study Population}

Patients were recruited between November 15, 2013, and January 15 , 2016. In total, 325 patients with first-time stroke were screened and 57 met the eligibility criteria. After randomization, 3 patients declined to participate before or at the time of intervention initiation. Therefore, a total of 54 patients ( $n=28$ for the real feedback group and $n=26$ for the sham feedback group) participated (figure 1).

Baseline clinical characteristics are shown in table 1. Patients in both groups were provided customary rehabilitative intervention for comparable periods with comparable average feedback signal values $(2.1 \pm 0.79$ and $1.8 \pm 0.67$, respectively). Forty-two patients $(77.8 \%)$ started intervention within 150 days from onset, while 12 patients $(22.2 \%)$ were in a more chronic period (table S1, doi.org/10.5061/dryad. sf $7 \mathrm{~m} 0 \mathrm{cg} 3 \mathrm{n})$. Baseline characteristics of both early recruitment and late recruitment patients were not significantly different except for the time since stroke onset and daily therapy time. Time from onset was $113.57 \pm 18.21$ days (median 112.0, interquartile range 99-28) in the early group and 1,341.79 \pm 881.59 days (median 1,332.25, interquartile range $638.25-1971, p<0.001)$ in the late group. Duration of rehabilitation intervention was significantly shorter among late intervention patients $(98.45 \pm 17.82$ minutes vs $136.67 \pm$ 

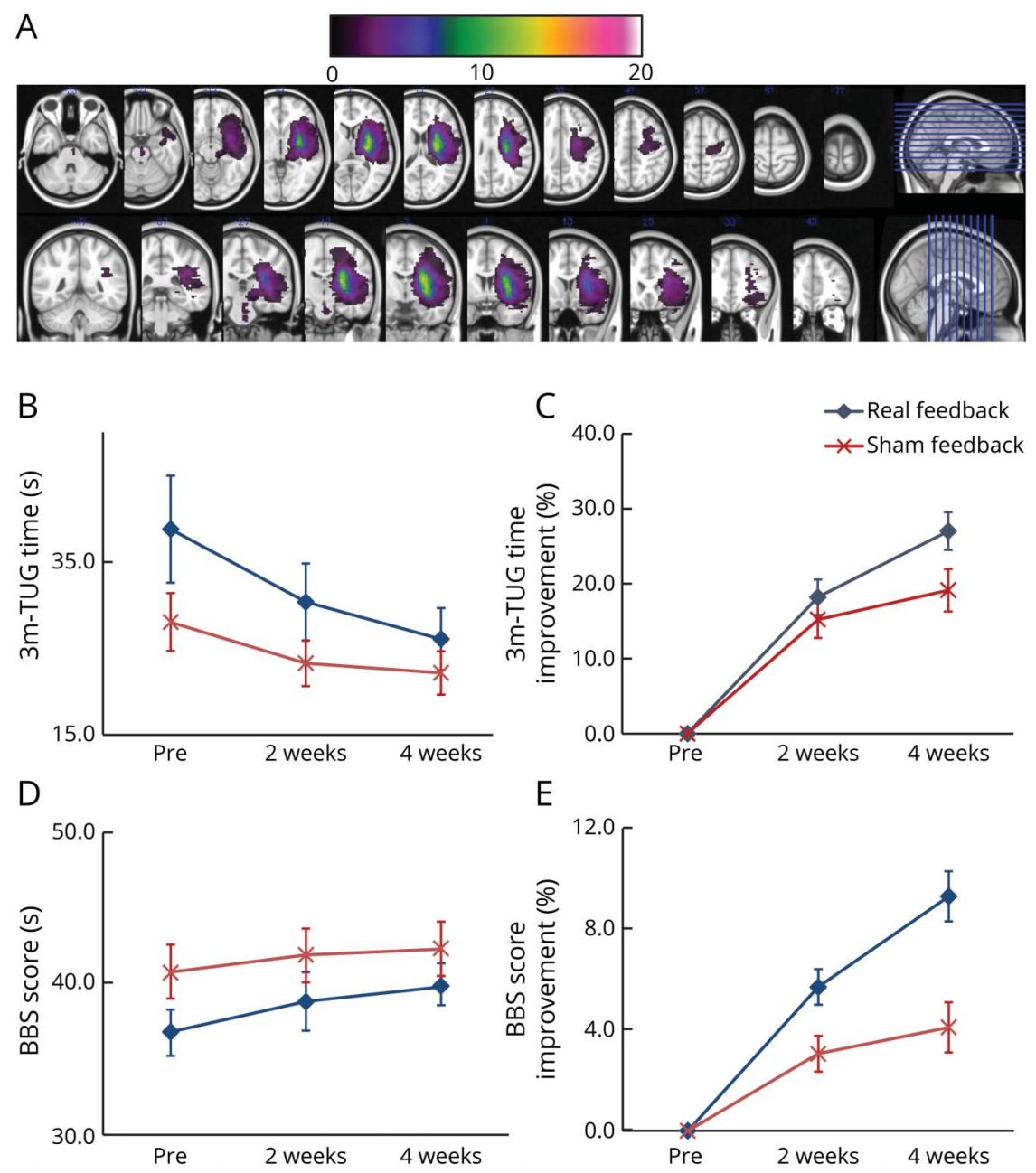

(A) Overlapped lesion maps reveal corticospinal
tract involvement at the level of the corona radi-
ata, internal capsule, and brainstem. (B, C) Three-
meter Timed Up and Go (TUG) test time was sig-
nificantly improved in the real feedback group
but not in the sham feedback group, with signifi-
cant interaction between time course and in-
tervention. (D, E) Berg Balance Scale (BBS) score
improved only in the real feedback group with
significant interaction between time course and

21.13 minutes, $p<0.001)$. However, there was no group difference in the mean duration of rehabilitation within both early and late intervention patients (early: real vs sham, 140.6 minutes vs 132.8 minutes, $p=0.281$; late: real vs sham, 100.08 minutes vs 96.00 minutes, $p=0.71$ ). Because early and late intervention patients had a similar baseline status in gait and balance characteristics, subsequent analyses were performed with the total sample. Lesion location analysis revealed that the participants' lesions mainly overlapped with the pyramidal tract (figure 3A).

\section{Primary Outcome Measures}

The results of clinical measures for gait and balance disturbance, activities of daily living, and motor impairment are shown in tables 2 and 3 and figure 3, B and C. As shown in table 2, a significant group difference was observed in TUG improvement from preintervention to post2. The group difference was 7.33 seconds in absolute value $\left(t_{52}=2.23, p=\right.$ $0.028)$ and $7.89 \%$ in recovery rate $\left(t_{52}=2.08, p=0.042\right)$. See the video for a representative patient. RM-ANCOVA revealed a significant effect of time $\left(F_{1.23,61.69}=4.91, p=0.024\right.$, partial $\eta^{2}=0.089$, with the Greenhouse-Geisser correction), with a significant interaction $\left(F_{1.23,61.69}=4.50, p=0.030\right.$, partial $\eta^{2}=$ 0.083 , with the Greenhouse-Geisser correction) observed between time (functional recovery pattern) and intervention (neurofeedback status). Within-group post hoc analysis revealed significant improvement of TUG only in the real feedback group at post 1 and post 2 compared with preintervention ( $p<0.001$ in both groups, respectively), with Bonferroni correction for multiple comparison (figure 3, B and $\mathrm{C}$ ).

\section{Secondary Outcome Measures}

Longitudinal changes in the secondary outcome measures are shown in tables 2 and 3. Although RM-ANCOVA revealed a nonsignificant effect over time $\left(F_{1.65,82.35}=2.04, p=0.145\right.$, partial $\eta^{2}=0.039$ with Greenhouse-Geisser correction), there was a significant interaction between time and neurofeedback intervention $\left(F_{1.65,82.35}=11.22, p<0.001\right.$, partial $\eta^{2}=0.183$ with Greenhouse-Geisser correction), with greater improvement in BBS in the real group (table 2 and figure 3, D and $\mathrm{E}$ ). Within-group post hoc analysis revealed a significant 
Table 2 Immediate and 2-Week Changes in Timed Up and Go (TUG) Test and Berg Balance Scale (BBS) in Both Groups

\begin{tabular}{|c|c|c|c|c|c|c|}
\hline & Pre & Post1 & Post2 & Post1 vs pre $(95 \% \mathrm{CI})^{d}$ & Post2 vs pre $(95 \% \mathrm{CI})^{d}$ & $\begin{array}{l}\text { Group difference at post2 } \\
(95 \% \mathrm{CI})\end{array}$ \\
\hline \multicolumn{7}{|c|}{$\begin{array}{l}\text { 3-m TUG, } \\
\text { s }\end{array}$} \\
\hline Real & $\begin{array}{l}38.74 \pm \\
33.14\end{array}$ & $\begin{array}{l}29.47 \pm \\
23.27^{a}\end{array}$ & $\begin{array}{l}25.90 \pm \\
18.89^{a}\end{array}$ & $\begin{array}{l}9.85 \pm 11.09 \mathrm{~s}^{\mathrm{d}}(5.06-14.65 \mathrm{~s}) \\
\mathrm{d} \\
(24.0 \pm 12.48 \% \\
\left.{ }^{\mathrm{d}}[13.24 \%-24.03 \%]\right)\end{array}$ & $\begin{array}{l}12.84 \pm 15.07 \mathrm{~s}^{\mathrm{d}}(7.29-18.59 \\
\mathrm{S})^{d} \\
(27.02 \pm 13.31 \% \\
\left.{ }^{d}[20.48 \%-33.02 \%]\right)\end{array}$ & $\begin{array}{l}7.32 \mathrm{~s}^{\mathrm{b}}(0.73-13.93 \mathrm{~s}) \\
\left(7.89 \%^{\mathrm{b}}[0.29 \%-15.48 \%]\right)^{d}\end{array}$ \\
\hline Sham & $\begin{array}{l}27.93 \pm \\
17.28\end{array}$ & $\begin{array}{l}23.67 \pm \\
13.84\end{array}$ & $\begin{array}{l}22.42 \pm \\
12.74\end{array}$ & $\begin{array}{l}4.81 \pm 7.31 \mathrm{~s}(1.49-8.14 \mathrm{~s}) \\
(17.19 \pm 12.54 \% \\
[11.49 \%-22.90 \%])^{d}\end{array}$ & $\begin{array}{l}5.42 \pm 7.64 \mathrm{~s}(0.46-11.30 \mathrm{~s}) \\
(19.14 \pm 14.52 \% \\
[12.91 \%-25.95 \%])^{d}\end{array}$ & \\
\hline \multicolumn{7}{|l|}{ BBS } \\
\hline Real & $36.71 \pm 9.48$ & $\begin{array}{l}38.64 \pm \\
9.37^{a}\end{array}$ & $\begin{array}{l}39.89 \pm \\
9.43^{a}\end{array}$ & $\begin{array}{l}2.13 \pm 1.29(1.57-2.69) \\
(6.08 \pm 3.80 \% \\
[4.44 \%-7.72 \%])^{d}\end{array}$ & $\begin{array}{l}3.18 \pm 1.63(2.45-3.90) \\
(9.27 \pm 5.25 \% \\
[6.91 \%-11.43 \%])^{d}\end{array}$ & $\begin{array}{l}1.68^{c}(0.85-2.50) \\
\left(4.89 \%^{c}[2.30 \%-7.49 \%]\right)^{d}\end{array}$ \\
\hline Sham & $40.77 \pm 7.78$ & $\begin{array}{l}41.88 \pm \\
7.41^{a}\end{array}$ & $\begin{array}{l}42.27 \pm \\
7.31^{a}\end{array}$ & $\begin{array}{l}1.05 \pm 1.02(0.58-1.51) \\
(2.93 \pm 3.05 \% \\
[1.54 \%-4.32 \%])^{d}\end{array}$ & $\begin{array}{l}1.50 \pm 1.36(0.75-2.25) \\
(4.49 \pm 4.11 \% \\
[2.15 \%-6.84 \%])^{d}\end{array}$ & \\
\hline \multicolumn{7}{|l|}{$\begin{array}{l}\text { Speed } \\
(\mathrm{m} / \mathrm{s})\end{array}$} \\
\hline Real & $0.53 \pm 0.36$ & $0.63 \pm 0.38^{a}$ & $0.68 \pm 0.38^{a}$ & $\begin{array}{l}0.10 \pm 0.08(0.07-0.14) \\
(27.35 \pm 25.03 \% \\
[16.53 \%-38.17 \%])^{d}\end{array}$ & $\begin{array}{l}0.15 \pm 0.11(0.10-0.19) \\
(38.26 \pm 32.78 \% \\
[24.63 \%-50.76 \%])^{d}\end{array}$ & $\begin{array}{l}0.023(-0.03-0.08) \\
(10.26 \%[-5.07 \%-25.60 \%])^{d}\end{array}$ \\
\hline Sham & $0.61 \pm 0.41$ & $0.68 \pm 0.42^{a}$ & $0.73 \pm 0.44^{a}$ & $\begin{array}{l}0.07 \pm 0.06(0.05-0.10) \\
(16.60 \pm 12.08 \% \\
[11.10 \%-22.10 \%])^{d}\end{array}$ & $\begin{array}{l}0.13 \pm 0.08(0.09-0.17) \\
(28.0 \pm 21.85 \% \\
[15.05 \%-42.18 \%])^{d}\end{array}$ & \\
\hline \multicolumn{7}{|l|}{ FIM total } \\
\hline Real & $\begin{array}{l}103.04 \pm \\
11.42\end{array}$ & $\begin{array}{l}108.00 \pm \\
9.66\end{array}$ & $\begin{array}{l}108.19 \pm \\
10.79\end{array}$ & $4.65 \pm 3.63(3.08-6.22)$ & $5.11 \pm 4.36(3.79-7.99)$ & $0.69(-1.54-2.92)$ \\
\hline Sham & $\begin{array}{l}102.88 \pm \\
12.17\end{array}$ & $\begin{array}{l}106.29 \pm \\
12.08\end{array}$ & $\begin{array}{l}107.30 \pm \\
11.10\end{array}$ & $3.38 \pm 3.10(1.97-4.79)$ & $4.42 \pm 3.68(3.06-7.46)$ & \\
\hline \multicolumn{7}{|l|}{$\begin{array}{l}\text { F-M } \\
\text { upper }\end{array}$} \\
\hline Real & $\begin{array}{l}33.56 \pm \\
18.12\end{array}$ & $\begin{array}{l}34.30 \pm \\
18.14\end{array}$ & $\begin{array}{l}35.15 \pm \\
18.38\end{array}$ & $0.91 \pm 1.20(0.39-1.43)$ & $1.67 \pm 2.46(0.20-2.96)$ & $0.79(-0.91-2.50)$ \\
\hline Sham & $\begin{array}{l}30.38 \pm \\
16.75\end{array}$ & $\begin{array}{l}31.62 \pm \\
17.64\end{array}$ & $\begin{array}{l}31.27 \pm \\
17.70\end{array}$ & $1.42 \pm 2.98(1.97-4.79)$ & $0.88 \pm 3.69(-0.44-2.42)$ & \\
\hline \multicolumn{7}{|l|}{$\begin{array}{l}\text { F-M } \\
\text { lower }\end{array}$} \\
\hline Real & $21.74 \pm 7.82$ & $22.30 \pm 7.74$ & $22.48 \pm 7.47$ & $0.74 \pm 1.10(0.27-1.21)$ & $0.82 \pm 1.09(-0.06-1.60)$ & $0.40(-0.65-1.44)$ \\
\hline Sham & $21.38 \pm 5.97$ & $22.04 \pm 6.26$ & $21.81 \pm 6.63$ & $0.90 \pm 1.26(0.33-1.48)$ & $0.42 \pm 2.51(-0.88-1.34)$ & \\
\hline \multicolumn{7}{|c|}{$\begin{array}{l}\text { Abbreviations: } \mathrm{Cl}=\text { confidence interval; } \mathrm{F}-\mathrm{M}= \\
\text { intervention; post } 1=\text { immediately after interv } \\
\text { vs pre = improvement at } 2 \text { weeks after interv } \\
\text { Data are presented as mean } \pm \mathrm{SD} \text {. } \\
\text { a } p<0.05 \text { compared with pre in post hoc ana } \\
{ }^{\mathrm{b}} p<0.05 \text { in group comparison. } \\
{ }^{c} p<0.001 \text { in group comparison. } \\
{ }^{\mathrm{d}} \mathrm{C} \text { Control with age and duration from onset. }\end{array}$} \\
\hline
\end{tabular}

longitudinal improvement although the effect was stronger in the real group.

There was a significant effect of time on gait speed $\left(F_{1.57,78.44}\right.$ $=7.97, p<0.001$, partial $\left.\eta^{2}=0.137\right)$, but interaction between time and intervention was not significant $\left(F_{1.57,78.44}=0.91, p\right.$ $=0.39$, partial $\eta^{2}=0.018$, table 3 ). Within-group post hoc analysis revealed a significant longitudinal improvement. Neither an over-time effect nor a group by time effect was observed (RM-ANCOVA) for FIM and F-M (table 3). 
Table 3 Adverse Events in the Real and Sham Feedback Groups

\begin{tabular}{lll}
\hline & $\begin{array}{l}\text { Real feedback } \\
(\mathbf{n}=\mathbf{2 9})\end{array}$ & $\begin{array}{l}\text { Sham feedback } \\
(\mathbf{n}=\mathbf{2 8})\end{array}$ \\
\hline Any pain & 13 patients & 13 patients \\
\hline Falls & $\begin{array}{l}5 \text { times/5 } \\
\text { patients }\end{array}$ & $\begin{array}{l}9 \text { times/8 } \\
\text { patients }\end{array}$ \\
\hline Infections & 4 patients & 6 patients \\
\hline $\begin{array}{l}\text { Upper respiratory tract } \\
\text { infection }\end{array}$ & 4 & 3 \\
\hline Paronychia & 0 & 2 \\
\hline Cellulitis & 0 & 1 \\
\hline Skin reactions & 3 patients & 3 patients \\
\hline Vascular events & 2 patients & 2 patients \\
\hline Other adverse events & $\begin{array}{l}\text { Hypoglycemia } \\
(1 \text { patient })\end{array}$ & $\begin{array}{l}\text { Epilepsy } \\
(1 \text { patient })\end{array}$ \\
\hline
\end{tabular}

In post hoc analysis for investigating the clinically robust improvement after intervention using the previously proposed minimal detectable change in TUG, 15 of 28 patients $(53.6 \%)$ in the real group improved more than 8 seconds in TUG, but only 5 of 26 patients (19.2\%) in the sham group achieved more than 8 seconds improvement $\left(\chi^{2}=6.82, d f=1\right.$, $p<0.01)$. Absolute risk reduction for nonsignificant improvement after neurofeedback intervention was $34.4 \%$ and number needed to treat was 2.91 .

\section{Motor Imagery-Related Cortical Activation in fNIRS Recording}

One patient from the real feedback group was excluded because of unavailability for the 6th (last) neurofeedback session. On comparing the first and 6th (last) neurofeedback sessions, cortical activation during walking imagery showed a significant increase in the unaffected SMA in the real feedback group (channels 21 and 22, $t_{52}=2.98$ and 3.15, respectively), whereas cortical activation changes during rising-up imagery did not reach statistical significance in either group. Group comparisons showed a significant difference in neurofeedback intervention-mediated change in walking imagery-related cortical activation in both unaffected and affected SMA (figure $4 \mathrm{~A}$, channels 21 and $28, t_{52}=3.23$ and 3.30 , respectively). A significant correlation was observed between BBS improvement and SMA activation change in the unaffected hemisphere (channel 21, $r=0.28, p<0.05$, figure $4 \mathrm{~B}$ ). Other clinical measures including TUG and gait speed were not significantly correlated with any cortical activation changes.

\section{Resting-State Functional Connectivity Change} rsfMRI analysis was conducted on 29 participants (14 in the real group and 15 in the sham feedback group). The real feedback group showed increased connectivity from the bilateral SMA to the affected cingulate gyrus ( 90 voxels, $t=5.93$, $\left.q_{\text {FDR-corr. }}=0.041\right)$ and the unaffected inferior frontal gyrus
(IFG) (93 voxels, $t=4.94, q_{\text {FDR-corr. }}=0.041$, figure $4 \mathrm{C}$ ). Regression analysis revealed that changes in resting-state connectivity between the bilateral SMA and the unaffected IFG correlated with an improvement of BBS scores (139 voxels, $t=4.14, q_{\mathrm{FDR}-\text { corr. }}=0.002$, Pearson $r=0.609$, figure $4 \mathrm{D})$. No significant clusters were observed between restingstate connectivity and changes in other clinical measures.

\section{Safety Measures}

None of the participants reported adverse effects related to the device or neurofeedback intervention. Thirteen patients in each group reported subjective pain including shoulder pain, headache, and lumbago, but all symptoms were present prior to participating in this study; none reported worsening of the symptoms after intervention. Five patients reported 5 falls in the real feedback group, while 8 reported 9 falls in the sham feedback group, with no severe secondary complications such as fractures or traumatic brain injury. Other reported adverse events included infections, skin reactions, and vascular events, but none was thought to be related to the intervention, and there were no significant differences between the groups (table 3).

\section{Classification of Evidence}

This exploratory double-blind randomized control study sought to evaluate the clinical efficacy of neurofeedback facilitation of gait-related motor imagery-associated SMA activation for augmenting recovery of poststroke gait and balance impairment, as assessed by TUG. Our data provide Class III evidence revealing the possible effect of novel neuromodulation for patients with first-time subcortical stroke with mild to moderate gait and balance disturbance.

\section{Discussion}

Although both groups carried out similar mental practice, our study revealed greater improvement of the TUG test in the intervention group, even after adjusting for covariates. In addition, only the real intervention group showed significantly increased imagery-related SMA activation and enhancement of resting-state connectivity between SMA and ventrolateral premotor area including IFG.

Neurofeedback is a technique enabling participants to regulate their own neural activity by presenting them with their real-time neural activity. This technique has been proposed as a therapeutic neuromodulation guiding or promoting beneficial physiologic processes in both healthy and neurologically impaired patients. ${ }^{21}$ We performed a randomized, doubleblinded, placebo-controlled, parallel-group, 2-center trial design, where we aimed to investigate fNIRS neurofeedback facilitation of gait imagery-related SMA activation and its role in augmenting gait and balance recovery in patients with stroke receiving ordinary physical training. On average, patients with neurofeedback intervention showed a significant TUG improvement of 12.8 seconds and 27.0\% (5.4 seconds 
Figure 4 Changes in Gait Imagery-Related Cortical Activation and Resting-State Connectivity From the Supplementary Motor Area (SMA) After Neurofeedback

A $(\text { Last }>\text { First })_{\text {Real }}>(\text { Last }>\text { First })_{\text {Sham }}$

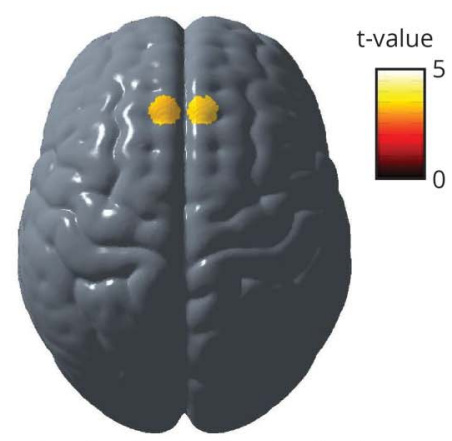

B

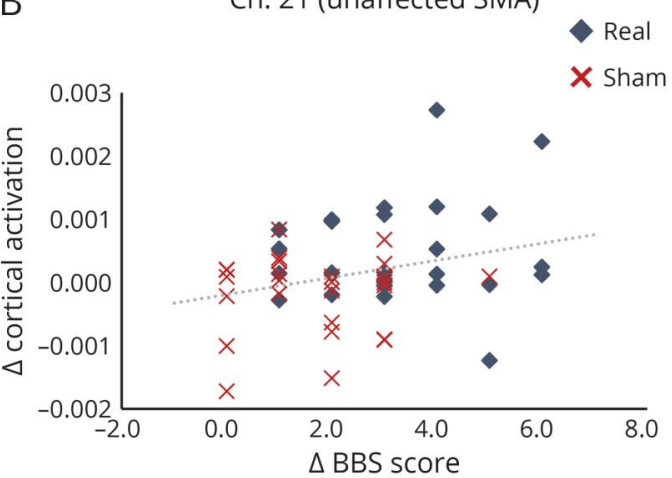

Affected hemisphere

\begin{tabular}{cccccc}
\hline Channel & MNI coordinate & BA & Cortical region & t-value & $q$ FDR-corr. \\
\hline 28 & $4 / 24 / 67$ & $6 / 8$ & Affected SMA & 3.3033 & $q=0.043$ \\
21 & $-10 / 24 / 67$ & 6 & Unaffected SMA & 3.2303 & $q=0.027$ \\
\hline
\end{tabular}

C

D

$(\text { Post }>\text { Pre })_{\text {Real }}>(\text { Post }>\text { Pre })_{\text {Sham }}$
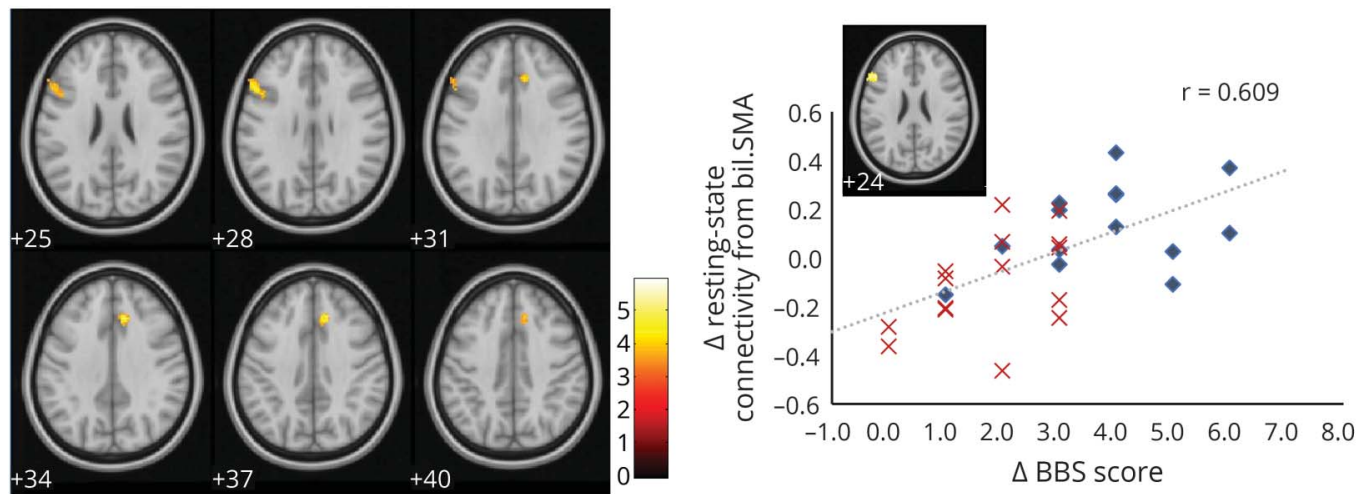

\begin{tabular}{cccccc}
\hline MNI coordinate & BA & Cortical region & Cluster volume & Peak t-value & $q$ FDR-corr. \\
\hline $12 / 28 / 36$ & 32 & Affected cingulate gyrus & 90 & 5.93 & $q=0.041$ \\
$-52 / 20 / 28$ & 44 & Unaffected IFG & 93 & 4.94 & $q=0.041$ \\
\hline
\end{tabular}

(A) There was a significant group difference in cortical activation changes after neurofeedback intervention. Functional near infrared spectroscopy neurofeedback intervention facilitated gait imagery-related SMA activation. (B) Clinical improvement of balance ability correlated significantly with the individual gait-related cortical activation changes, suggesting an effect of SMA facilitation on balance ability. (C) Resting-state fMRI analysis revealed that SMA facilitation by neurofeedback enhances functional connectivity between the SMA and several motor-related cortical areas, including the affected anterior cingulate gyrus and the unaffected inferior frontal gyrus (IFG). (D) Resting-state functional connectivity changes between the SMA and the unaffected IFG significantly correlated with individual balance improvement. BA = Brodmann area; BBS = Berg Balance Scale; Ch = channels in functional near infrared spectroscopy recording; FDR = false discovery rate; $\mathrm{MNI}=$ Montreal Neurologic Institute.

and $19.1 \%$ improvement in the sham group) and BBS improvement of 3.18 points and $9.27 \%$ (1.5 points and $4.5 \%$ improvement in the sham group). Although the MICD for the TUG were not established, our findings showed that only the real group showed greater improvement than the previously proposed minimal detectable changes ( 8.0 seconds in TUG and 2.7 points in BBS, respectively). ${ }^{22}$ These findings suggest that neurofeedback facilitation of the SMA may have a clinically relevant effect on poststroke gait and balance recovery. We also found that walking speed increased in both the intervention and placebo groups at a level exceeding the proposed minimal detectable changes, although this effect did not reach significance in our sample. In addition, we found no group differences in the changes of F-M in the upper and lower limbs, highlighting the specific behavioral effect of SMA neurofeedback. Importantly, no severe adverse effects were found in either of the groups, and there was no group difference observed in any specific adverse effect. This suggests the safety and feasibility of fNIRS neurofeedback for patients with stroke as a viable treatment option for poststroke gait and balance impairment in the future.

Neurofeedback techniques have been introduced in stroke rehabilitation to facilitate functional recovery of upper limb 
paresis, ${ }^{8}$ unilateral neglect, ${ }^{23}$ and cognitive deficit. ${ }^{24}$ A few preliminary studies suggesting the possible efficacy of neurofeedback in improving dual-task gait after stroke ${ }^{25,26}$ have emerged over the years. Because functional reorganization of the hierarchical neural network for regulating human bipedal gait and balance is essential to gait and balance recovery after stroke, ${ }^{15,27}$ previous neuromodulation studies have targeted several areas within this network, including the primary leg motor area, ${ }^{28-30} \mathrm{SMA}^{31}$ and cerebellum. ${ }^{32,33}$ Of these areas, we selected the SMA as a target cortical area because previous neuroimaging studies have specifically revealed involvement of the SMA and its descending pathway in poststroke gait and balance recovery. ${ }^{3,11,16}$ In addition, our preliminary proof-ofconcept study showed a positive effect of SMA facilitation by fNIRS neurofeedback on individual balance ability. ${ }^{17}$

There was also a significant correlation between the imageryrelated SMA activation change and balance recovery in the real feedback group (figure 4). This is in line with our previous pilot study for poststroke upper limb paresis. ${ }^{10}$ Considering previous findings that postural perturbation-related SMA activation change in the unaffected hemisphere is significantly correlated with balance recovery, ${ }^{11}$ our findings suggest that neuromodulation of the SMA may augment gait and balance recovery. Our rsfMRI findings suggest a fNIRS neurofeedback effect on the SMA-related resting-state functional network. Specifically, neurofeedback facilitation of the gait imagery-related SMA activation enhanced functional connectivity of the SMA with ventral premotor (PMv) and anterior cingulate cortex (ACC) (figure 4C). Considering the dense anatomical connections between the ACC and SMA, ${ }^{34}$ and neuroimaging findings that the ACC becomes activated during gait and balance task together with the SMA, ${ }^{35,36}$ the facilitation of the network involving both SMA and ACC is likely to be associated with better gait and balance ability. Our findings also suggest that connectivity changes between the SMA and PMv significantly correlate with balance recovery (figure 4D). Previous studies have reported the presence of anatomical connections between the $\mathrm{PMv}$ and the hindlimb area of the SMA, both of which were activated in the imagery associated with stepping over an obstacle or gait termination. ${ }^{37}$ In addition, the PMv is known to be a part of the mirror neuron system and may be involved in observational motor learning. A recent study revealed that SMA involvement in balance imagery and additional action observation increases cortical involvement including the PMv, dorsal premotor, primary motor, and basal ganglia. ${ }^{38}$ These findings suggest that the enhanced functional network including the SMA and PMv, by facilitation of the SMA activation during gait and balance imagery, may partly explain the augmented gait and balance recovery.

Unlike our previous proof-of-concept study, ${ }^{17}$ participants in this study performed mental practice using gait and balance motor imagery. Because there is ample evidence that motor imagery involves a motor network similar to that of motor execution, mental practice may work as a substitutional intervention for patients with stroke. ${ }^{39}$ However, the results of a recent meta-analysis of mental practice-based intervention were inconclusive. ${ }^{40}$ Previous studies have revealed that interindividual variability in motor imagery skill may affect motor imagery-related cortical activation ${ }^{41}$ and efficacy of mental practice. ${ }^{42}$ It is possible that people who could effectively recruit motor imagery-related cortical networks can respond well to mental practice-based intervention. In this study we applied only six 10-minute sessions of motor imagery training with NIRS-NFB, but facilitation of the motor imagery-related neural network was evident and correlated with clinical efficacy. These findings suggest fNIRS-NFB might augment effectiveness of mental practice using motor imagery.

This study has some limitations. First, several studies demonstrated that fMRI- or EEG-neurofeedback learning effects on brain activity last over a year. ${ }^{43-45}$ Therefore, our relatively short follow-up period precluded examination of long-term effects of fNIRS neurofeedback. It is also difficult to decide on the appropriate amount and frequency of neurofeedback intervention. To confirm the clinical efficacy of fNIRS-NFB, further studies are needed with longer follow-up or additional control, such as equivalent amount of rehabilitative intervention. Second, because we only recruited patients who could walk with minimal assistance, it is possible that fNIRS neurofeedback is effective only for patients with moderate to mild impairments. However, based on the theory of usedependent plasticity, ${ }^{46}$ neuromodulation may be more beneficial for more severely affected patients. Third, because the duration between onset and baseline clinical status varied considerably, the results could differ for more homogeneous samples. This, together with relatively small sample size in our study, could result in false-positive results or associations, suggesting the need for larger samples. Fourth, because MRI scanners at the 2 facilities were different in magnet power, manufacturer, and protocol, we used only the data from the facility with the larger sample size (Morinomiya Hospital) for further rsfMRI analysis. Finally, because recent studies investigating EEG neurofeedback on psychological disorders have failed to reveal superior efficacy compared to placebo neurofeedback or conventional therapy, ${ }^{47,48}$ the importance of double-blinded, placebo-controlled clinical trials has been emphasized. However, it remains possible that participants in the sham group could have recognized that the neurofeedback they were presented with did not reflect their own signal. As argued in a recent review, it is difficult to design a study that completely excludes the possible confounding effects in neurofeedback, ${ }^{49}$ and further studies using multiple intervention settings are warranted.

Our findings suggest that fNIRS-NFB augments poststroke gait and balance recovery by modulating the SMA and related functional network. Although further studies are needed to confirm our findings and clinical effect, the present study suggests the feasibility and efficacy of fNIRS neurofeedback for patients with stroke with gait and balance impairments. 


\section{Acknowledgment}

Editorial support, in the form of medical writing, assembling of tables, creating high-resolution images based on detailed directions, collating author comments, copy editing, fact checking, and referencing was provided by Editage and Enago.

\section{Study Funding}

Supported by Health and Labor Sciences Research Grants for Comprehensive Research on Persons with Disabilities (JP15652696, JP19dk0310093) and the Development of Medical Devices and Systems for Advanced Medical Services (JP18he0402255, JP19hk0102063) from the Japan Agency for Medical Research and Development.

\section{Disclosure}

Dr. Mihara reports grants and personal fees from Sumitomo Dainippon Pharma; grants from Japan Blood Products Organization, Kyowa Hakko Kirin Co., Ltd., Daiichi Sankyo, and The Osaka Medical Research Foundation for Intractable Diseases; personal fees from Otsuka Pharmaceutical Co., Ltd., Novartis, and Shimadzu Corp., outside the submitted work; grants from The Japan Agency for Medical Research and Development (AMED) during the conduct of the study; and has a patent pending (PCT2015065270/W2016189701). Dr. Fujimoto reports no disclosures. Dr. Hattori reports personal fees from Yukokai Medical Corp., Wakakoukai Medical Corp., Kinshukai Medical Corp., Kyowakai Medical Corp., Incorporated NPO Mirai Process, and Green Hospital Supply, Inc., outside the submitted work; and grants from AMED during the conduct of the study. Dr. Otomune, Dr. Kajiyama, and Dr. Konaka report no disclosures. Dr. Watanabe reports grants from AMED during the conduct of the study. Dr. Hiramatsu reports no disclosures. Dr. Sunada reports grants from Sumitomo Dainippon Pharma, Kyowa Hakko Kirin Co., Ltd., Daiichi Sankyo Co. Ltd., and Japan Blood Products Organization, outside the submitted work. Dr. Miyai reports grants from AMED during the conduct of the study and has a patent pending (PCT2015065270/W2016189701). Dr. Mochizuki reports personal fees from Sanofi KK, MSD KK, Otsuka Pharmaceutical, Daiichi Sankyo Co. Ltd., Pfizer Japan Inc., Bayer Yakuhin, Ltd., and AbbVie GK outside the submitted work; and grants from AMED during the conduct of the study. Go to Neurology.org/N for full disclosures.

\section{Publication History}

Received by Neurology December 28, 2019. Accepted in final form March 1, 2021.

Appendix Authors

\begin{tabular}{|c|c|c|}
\hline Name & Location & Contribution \\
\hline $\begin{array}{l}\text { Masahito } \\
\text { Mihara, } \\
\text { MD, PhD }\end{array}$ & $\begin{array}{l}\text { Kawasaki Medical School, } \\
\text { Osaka University Graduate } \\
\text { School of Medicine }\end{array}$ & $\begin{array}{l}\text { Study design and } \\
\text { conceptualization, patient } \\
\text { recruitment, data collection } \\
\text { and analysis, statistical } \\
\text { analysis, manuscript draft } \\
\text { and revision }\end{array}$ \\
\hline
\end{tabular}

Appendix (continued)

\begin{tabular}{|c|c|c|}
\hline Name & Location & Contribution \\
\hline $\begin{array}{l}\text { Hiroaki } \\
\text { Fujimoto, } \\
\text { MD, PhD }\end{array}$ & Morinomiya Hospital & $\begin{array}{l}\text { Data collection and } \\
\text { analysis, patient } \\
\text { recruitment }\end{array}$ \\
\hline $\begin{array}{l}\text { Noriaki } \\
\text { Hattori, } \\
\text { MD, PhD }\end{array}$ & $\begin{array}{l}\text { Osaka University Global } \\
\text { Center for Medical } \\
\text { Engineering and } \\
\text { Informatics }\end{array}$ & $\begin{array}{l}\text { Study design, data } \\
\text { collection and analysis, } \\
\text { manuscript draft }\end{array}$ \\
\hline $\begin{array}{l}\text { Hironori } \\
\text { Otomune, } \\
\text { MD }\end{array}$ & $\begin{array}{l}\text { Osaka University Graduate } \\
\text { School of Medicine }\end{array}$ & Data collection and analysis \\
\hline $\begin{array}{l}\text { Yuta } \\
\text { Kajiyama, } \\
\text { MD }\end{array}$ & $\begin{array}{l}\text { Osaka University Graduate } \\
\text { School of Medicine }\end{array}$ & $\begin{array}{l}\text { Data collection and } \\
\text { analysis, patient } \\
\text { recruitment }\end{array}$ \\
\hline $\begin{array}{l}\text { Kuni } \\
\text { Konaka, } \\
\text { MD, PhD }\end{array}$ & $\begin{array}{l}\text { Osaka University Graduate } \\
\text { School of Medicine }\end{array}$ & $\begin{array}{l}\text { Data analysis, } \\
\text { randomization }\end{array}$ \\
\hline $\begin{array}{l}\text { Yoshiyuki } \\
\text { Watanabe, } \\
\text { MD, PhD }\end{array}$ & $\begin{array}{l}\text { Osaka University Graduate } \\
\text { School of Medicine }\end{array}$ & $\begin{array}{l}\text { Study design, data } \\
\text { collection and analysis }\end{array}$ \\
\hline $\begin{array}{l}\text { Yuichi } \\
\text { Hiramatsu, } \\
\text { MSc, PhD }\end{array}$ & Morinomiya Hospital & Data collection and analysis \\
\hline $\begin{array}{l}\text { Yoshihide } \\
\text { Sunada, } \\
\text { MD, PhD }\end{array}$ & Kawasaki Medical School & Data analysis \\
\hline $\begin{array}{l}\text { Ichiro } \\
\text { Miyai, MD, } \\
\text { PhD }\end{array}$ & Morinomiya Hospital & $\begin{array}{l}\text { Study design, data analysis, } \\
\text { manuscript draft }\end{array}$ \\
\hline $\begin{array}{l}\text { Hideki } \\
\text { Mochizuki } \\
\text { MD, PhD }\end{array}$ & $\begin{array}{l}\text { Osaka University Graduate } \\
\text { School of Medicine }\end{array}$ & $\begin{array}{l}\text { Study design, manuscript } \\
\text { revision }\end{array}$ \\
\hline
\end{tabular}

\section{References}

1. Hyndman D, Ashburn A, Stack E. Fall events among people with stroke living in the community: circumstances of falls and characteristics of fallers. Arch Phys Med Rehabil. 2002;83(2):165-170.

2. Schmid AA, Van Puymbroeck M, Altenburger PA, Miller KK, Combs SA, Page SJ. Balance is associated with quality of life in chronic stroke. Top Stroke Rehabil. 2013; 20(4):340-346.

3. Jang SH, Chang CH, Lee J, Kim CS, Seo JP, Yeo SS. Functional role of the corticoreticular pathway in chronic stroke patients. Stroke. 2013;44(4):1099-1104.

4. Jang SH. The recovery of walking in stroke patients: a review. Int J Rehabil Res. 2010; 33(4):285-289.

5. Jorgensen HS, Nakayama H, Raaschou HO, Olsen TS. Recovery of walking function in stroke patients: the Copenhagen Stroke Study. Arch Phys Med Rehabil. 1995;76(1):27-32.

6. Kwakkel G, Kollen B, Twisk J. Impact of time on improvement of outcome after stroke. Stroke. 2006;37(9):2348-2353.

7. Chieffo R, Comi G, Leocani L. Noninvasive neuromodulation in poststroke gait disorders: rationale, feasibility, and state of the art. Neurorehabil Neural Repair. 2016; 30(1):71-82.

8. Cervera MA, Soekadar SR, Ushiba J, et al. Brain-computer interfaces for poststroke motor rehabilitation: a meta-analysis. Ann Clin Transl Neurol. 2018;5(5):651-663.

9. Mihara M, Miyai I, Hattori N, et al. Neurofeedback using real-time near-infrared spectroscopy enhances motor imagery related cortical activation. PLoS One. 2012; 7(3):e32234.

10. Mihara M, Hattori N, Hatakenaka M, et al. Near-infrared spectroscopy-mediated neurofeedback enhances efficacy of motor imagery-based training in poststroke victims: a pilot study. Stroke. 2013;44:(4)1091-1098.

11. Fujimoto H, Mihara M, Hattori N, et al. Cortical changes underlying balance recovery in patients with hemiplegic stroke. Neuroimage. 2014;85Pt 1:547-554.

12. Ota $Y$, Takamoto K, Urakawa $S$, et al. Motor imagery training with neurofeedback from the frontal pole facilitated sensorimotor cortical activity and improved hand dexterity. Front Neurosci. 2020;14:34.

13. Le Q, Qu Y, Tao Y, Zhu S. Effects of repetitive transcranial magnetic stimulation on hand function recovery and excitability of the motor cortex after stroke: a metaanalysis. Am J Phys Med Rehabil. 2014;93:(5)422-430. 
14. Muri RM, Cazzoli D, Nef T, Mosimann UP, Hopfner S, Nyffeler T. Non-invasive brain stimulation in neglect rehabilitation: an update. Front Hum Neurosci. 2013;7:248

15. Takakusaki K. Neurophysiology of gait: from the spinal cord to the frontal lobe. Mov Disord. 2013;28(11):1483-1491.

16. Mihara M, Miyai I, Hatakenaka M, Kubota K, Sakoda S. Role of the prefrontal cortex in human balance control. Neuroimage. 2008;43(2):329-336.

17. Fujimoto H, Mihara M, Hattori N, et al. Neurofeedback-induced facilitation of the supplementary motor area affects postural stability. Neurophotonics. 2017;4(4): 045003.

18. Podsiadlo D, Richardson S. The Timed "Up \& Go": a test of basic functional mobility for frail elderly persons. J Am Geriatr Soc. 1991;39(2):142-148.

19. Hafsteinsdottir TB, Rensink M, Schuurmans M. Clinimetric properties of the Timed up and Go Test for patients with stroke: a systematic review. Top Stroke Rehabil. 2014; 21(3):197-210.

20. Mihara M, Miyai I, Hattori N, et al. Cortical control of postural balance in patients with hemiplegic stroke. Neuroreport. 2012;23(5):314-319.

21. Sitaram R, Ros T, Stoeckel L, et al. Closed-loop brain training: the science of neurofeedback. Nat Rev Neurosci. 2017;18(2):86-100.

22. Alghadir AH, Al-Eisa ES, Anwer S, Sarkar B. Reliability, validity, and responsiveness of three scales for measuring balance in patients with chronic stroke. BMC Neurol. 2018; 18(1):141

23. Ros T, Michela A, Bellman A, Vuadens P, Saj A, Vuilleumier P. Increased alpharhythm dynamic range promotes recovery from visuospatial neglect: a neurofeedback study. Neural Plast. 2017;2017:7407241.

24. Renton T, Tibbles A, Topolovec-Vranic J. Neurofeedback as a form of cognitive rehabilitation therapy following stroke: a systematic review. PLoS One. 2017;12(5): e0177290

25. Chung E, Park SI, Jang YY, Lee BH. Effects of brain-computer interface-based functional electrical stimulation on balance and gait function in patients with stroke: preliminary results. J Phys Ther Sci. 2015;27(2):513-516.

26. Lee YS, Bae SH, Lee SH, Kim KY. Neurofeedback training improves the dual-task performance ability in stroke patients. Tohoku J Exp Med. 2015;236(1):81-88.

27. Yang JF, Gorassini M. Spinal and brain control of human walking: implications for retraining of walking. Neuroscientist. 2006;12(5):379-389.

28. Seo HG, Lee WH, Lee SH, Yi Y, Kim KD, Oh BM. Robotic-assisted gait training combined with transcranial direct current stimulation in chronic stroke patients: a pilot double-blind, randomized controlled trial. Restor Neurol Neurosci. 2017;35(5): 527-536.

29. Wang RY, Tseng HY, Liao KK, Wang CJ, Lai KL, Yang YR. rTMS combined with taskoriented training to improve symmetry of interhemispheric corticomotor excitability and gait performance after stroke: a randomized trial. Neurorehabil Neural Repair. 2012;26(3):222-230.

30. Wang RY, Wang FY, Huang SF, Yang YR. High-frequency repetitive transcranial magnetic stimulation enhanced treadmill training effects on gait performance in individuals with chronic stroke: a double-blinded randomized controlled pilot trial. Gait Posture. 2018;68:382-387.

31. Manji A, Amimoto K, Matsuda T, Wada Y, Inaba A, Ko S. Effects of transcranial direct current stimulation over the supplementary motor area body weight-supported treadmill gait training in hemiparetic patients after stroke. Neurosci Lett. 2018;662: 302-305
32. Koch G, Bonni S, Casula EP, et al. Effect of cerebellar stimulation on gait and balance recovery in patients with hemiparetic stroke: a randomized clinical trial. JAMA Neurol. 2019;76(2):170-178

33. Picelli A, Chemello E, Castellazzi P, et al. Combined effects of cerebellar transcranial direct current stimulation and transcutaneous spinal direct current stimulation on robot-assisted gait training in patients with chronic brain stroke: a pilot, single blind, randomized controlled trial. Restor Neurol Neurosci. 2018;36(2):161-171.

34. Vergani F, Lacerda L, Martino J, et al. White matter connections of the supplementary motor area in humans. J Neurol Neurosurg Psychiatry. 2014;85(12):1377-1385.

35. Iseki K, Hanakawa T, Shinozaki J, Nankaku M, Fukuyama H. Neural mechanisms involved in mental imagery and observation of gait. Neuroimage. 2008;41(3) 1021-1031.

36. Knaepen K, Mierau A, Tellez HF, Lefeber D, Meeusen R. Temporal and spatial organization of gait-related electrocortical potentials. Neurosci Lett. 2015;599:75-80.

37. Wang J, Wai Y, Weng Y, et al. Functional MRI in the assessment of cortical activation during gait-related imaginary tasks. J Neural Transm. 2009;116(9):1087-1092.

38. Taube W, Mouthon M, Leukel C, Hoogewoud HM, Annoni JM, Keller M. Brain activity during observation and motor imagery of different balance tasks: an fMRI study. Cortex. 2015;64:102-114.

39. Bajaj S, Butler AJ, Drake D, Dhamala M. Brain effective connectivity during motorimagery and execution following stroke and rehabilitation. Neuroimage Clin. 2015;8 $572-582$.

40. Guerra ZF, Lucchetti ALG, Lucchetti G. Motor imagery training after stroke: a systematic review and meta-analysis of randomized controlled trials. J Neurol Phy Ther. 2017;41(4):205-214.

41. van der Meulen M, Allali G, Rieger SW, Assal F, Vuilleumier P. The influence of individual motor imagery ability on cerebral recruitment during gait imagery. Hum Brain Mapp. 2014;35(2):455-470.

42. Ruffino C, Papaxanthis C, Lebon F. The influence of imagery capacity in motor performance improvement. Exp Brain Res. 2017;235(10):3049-3057.

43. Kouijzer ME, de Moor JM, Gerrits BJ, Buitelaar JK, van Schie HT. Long-term effects of neurofeedback treatment in autism. Res Autism Spectr Disord. 2009;3(2):496-501.

44. Robineau F, Rieger SW, Mermoud C, et al. Self-regulation of inter-hemispheric visual cortex balance through real-time fMRI neurofeedback training. Neuroimage. 2014, 100:1-14

45. Vernon D, Frick A, Gruzelier J. Neurofeedback as a treatment for ADHD: a methodological review with implications for future research. J Neurother. 2004;8(2):53-82.

46. Kreisel SH, Hennerici MG, Bazner H. Pathophysiology of stroke rehabilitation: the natural course of clinical recovery, use-dependent plasticity and rehabilitative outcome. Cerebrovasc Dis. 2007;23(4):243-255.

47. Schabus M, Griessenberger H, Gnjezda MT, Heib DPJ, Wislowska M, Hoedlmoser K. Better than sham? A double-blind placebo-controlled neurofeedback study in primary insomnia. Brain. 2017;140(4):1041-1052.

48. Schonenberg M, Wiedemann E, Schneidt A, et al. Neurofeedback, sham neurofeedback, and cognitive-behavioural group therapy in adults with attention-deficit hyperactivity disorder: a triple-blind, randomised, controlled trial. Lancet Psychiatry. 2017;4(9):673-684.

49. Sorger B, Scharnowski F, Linden DEJ, Hampson M, Young KD. Control freaks: towards optimal selection of control conditions for fMRI neurofeedback studies. Neuroimage. 2019;186:256-265. 


\section{Neurology}

\section{Effect of Neurofeedback Facilitation on Poststroke Gait and Balance Recovery: A Randomized Controlled Trial}

Masahito Mihara, Hiroaki Fujimoto, Noriaki Hattori, et al.

Neurology 2021;96;e2587-e2598 Published Online before print April 20, 2021

DOI 10.1212/WNL.0000000000011989

This information is current as of April 20, 2021

Neurology ${ }^{\circledR}$ is the official journal of the American Academy of Neurology. Published continuously since 1951, it is now a weekly with 48 issues per year. Copyright Copyright (C) 2021 The Author(s). Published by Wolters Kluwer Health, Inc. on behalf of the American Academy of Neurology.. All rights reserved. Print ISSN: 0028-3878. Online ISSN: 1526-632X.

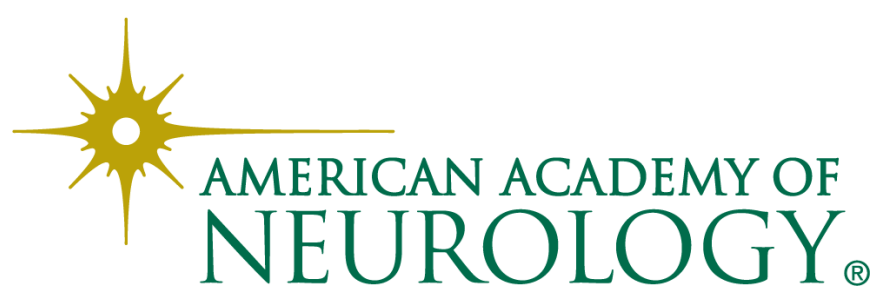




\section{Updated Information \& Services}

References

Citations

Subspecialty Collections

Permissions \& Licensing

Reprints including high resolution figures, can be found at: http://n.neurology.org/content/96/21/e2587.full

This article cites 49 articles, 4 of which you can access for free at: http://n.neurology.org/content/96/21/e2587.full\#ref-list-1

This article has been cited by 1 HighWire-hosted articles: http://n.neurology.org/content/96/21/e2587.full\#\#otherarticles

This article, along with others on similar topics, appears in the following collection(s):

\section{All Cerebrovascular disease/Stroke}

http://n.neurology.org/cgi/collection/all_cerebrovascular_disease_strok e

\section{Class III}

http://n.neurology.org/cgi/collection/class_iii

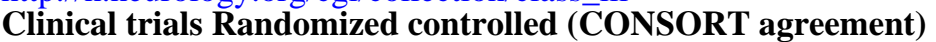

http://n.neurology.org/cgi/collection/clinical_trials_randomized_contro lled_consort_agreement

fMR $\mathbf{R}$

http://n.neurology.org/cgi/collection/fmri

Near Infrared Spectroscopy (NIRS)

http://n.neurology.org/cgi/collection/near_infrared_spectroscopy_nirs Plasticity

http://n.neurology.org/cgi/collection/plasticity

Information about reproducing this article in parts (figures,tables) or in its entirety can be found online at:

http://www.neurology.org/about/about_the_journal\#permissions

Information about ordering reprints can be found online:

http://n.neurology.org/subscribers/advertise

Neurology ${ }^{\circledR}$ is the official journal of the American Academy of Neurology. Published continuously since 1951, it is now a weekly with 48 issues per year. Copyright Copyright ( 2021 The Author(s). Published by Wolters Kluwer Health, Inc. on behalf of the American Academy of Neurology.. All rights reserved. Print ISSN: 0028-3878. Online ISSN: 1526-632X.

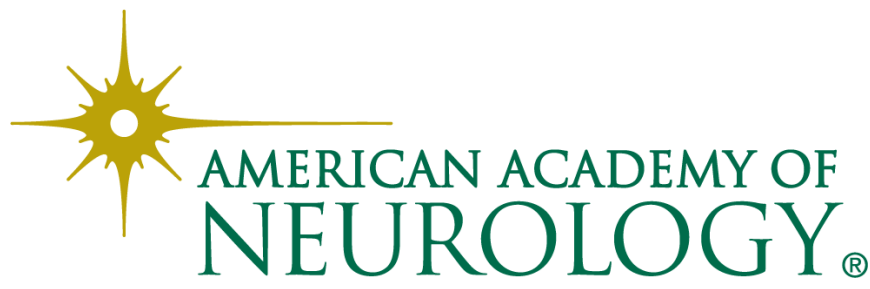

